\title{
Discourse Interpretation: A Deconstructive, Reader-oriented Approach to Critical Discourse Analysis
}

\author{
Ayman Farid Khafaga \\ Department of English, College of Science and Humanities, Prince Sattam bin Abdulaziz University, Kingdom of Saudi Arabia \\ $\&$ \\ Department of English, Faculty of Arts and Humanities, Suez Canal University, Egypt \\ E-mail: a.khafaga@psau.edu.sa
}

Received: 24-09-2016

Published: 01-03-2017
Accepted: 03-12-2016

doi:10.7575/aiac.ijalel.v.6n.2p.138
Advance Access Published: January 2017

URL: http://dx.doi.org/10.7575/aiac.ijalel.v.6n.2p.138

This research project was supported by the Deanship of Scientific Research at Prince Sattam Bin Abdulaziz University under the research project No. 4063/02/2015.

\begin{abstract}
This paper is based on the premise that discourse is always under the influence of different ideological readings which not only formulate its meaning but inspire various interpretations as well; hence, it needs a theoretical cover that could justify its multiplicity of meaning. This paper, therefore, discusses the possibility of introducing a deconstructive, reader-oriented approach (DRA) to Critical Discourse Analysis (CDA) as a model of discourse interpretation. The paper tries to appraise the theoretical framework of CDA and to offer an overview of the fundamental propels of its interpretative task in the light of two poststructuralist literary theories: the deconstruction theory and the reception theory. The paper also endeavours to emphasize the deconstructive nature of CDA by shedding lights on its relationship with the above mentioned theories. The conclusion drawn from this paper shows that introducing a deconstructive, reader-oriented approach to $\mathrm{CDA}$ is relevant to the latter's interpretative nature enough to diminish a part of the criticism levelled against its interpretative framework concerning plurality of meaning; and to establish some sort of exoneration for its theoretical shortcomings. The paper recommends that DRA will bridge the gap between theory and practice as it offers a theoretical base to discourse which could advocate its critiques regarding diversity of interpretation.
\end{abstract}

Keywords: Critical discourse analysis, deconstructive, reader-oriented approach, deconstructionism, interpretation, responsiveness

\section{Introduction}

Starting from the assumption that Critical Discourse Analysis (CDA) is "socially constructed as well as socially conditioned," (Blommaert, 2005a, p. 25) it follows that this approach gives priority not only to the linguistic features of texts but also to the manner through which a text can be read and received, and the social circumstances under which it is produced and consumed. This paper however will refrain itself from illustrating the meaning or the framework of CDA as a school of interpreting discourse, nor will it discuss the goals, the objectives, or the principles of the discipline because these concepts have adequately been studied and extensively explained by scholars, such as Fairclough (1989; 1995; 2009; 2010; 2013), Van Dijk (1989; 1993; 2014), Weiss and Wodak (2003); and others. The primary aim of this paper is to explore the possibility of considering CDA as a model of discourse interpretation by introducing a deconstructive, reader-oriented approach (henceforth DRA) to this paradigm. The purpose is to present CDA beyond its critical paradigm of analysis and shed lights on its deconstructive nature. This paper will thus contribute to the advancement of the theoretical critique on the concept of discourse and will propose a reconceptualization of it. The paper thus proposes to add a new dimension to CDA, determining its close relationship with poststructuralist literary theories: the deconstruction theory and the reception theory.

This proposed new perspective of CDA attempts to broaden its theoretical framework and to align it with what can be considered key tenets of the deconstruction and the reception theories. It can also contribute to a more compromising settlement to the argumentative controversy among CD analysts regarding the theoretical interpretative nature of CDA. This paper, therefore, tries to achieve the following goals:

1- To contribute to the theoretical discussion on critical discourse analysis by exploring the possibilities of broadening its theoretical framework.

2- To emphasize the reciprocal relationship between CDA as a linguistic school and the poststructuralist literary theories, namely the deconstruction theory and the reception theory. 
3- To introduce a deconstructive, reader-oriented approach to CDA, which can enrich its framework, open new insights in the discipline, and alleviate inconsistencies in the controversial issue of interpretation.

DRA owes much to the work of many other theorists who have contributed efficaciously to CDA; however, it undoubtedly needs further consolidation and refinement. Nevertheless, the paper's sole aim has been to outline this new approach in an attempt to broaden CDA's theoretical framework and to settle a compromise to some of the critiques against CDA which have hitherto been left unresolved.

\section{Theoretical Background}

\subsection{Critical Discourse Analysis}

Critical discourse analysis (CDA) has established itself as an independent school of discourse analysis since the late 1970's. It has been discussed by many linguists, such as Fairclough (1989; 1995a; 2009; 2010; 2013),

Fairclough et al. (2003; 2011), Van Dijk (1993; 1996; 2001; 2014), Weiss and Wodak (2003), Wodak and Meyer (2009), to mention just a few names. Compared to the large body of research on CDA, little has been discussed about its relationship with postmodern literary theories, in general, and both the deconstruction theory and the reception theory, in particular. Investigating the roots of CDA shows that this approach can be dated back not only to linguistic origins but to literary ones as well. Linguistically, CDA can be traced back to both critical linguistics and linguistic criticism (Fowler, 1986; 1996; Fowler \& Kress, 1979; Kress, 1996; Teo, 2000). CDA can also be said to have a relationship with the deconstruction theory and the reception theory. This relationship between CDA and these literary and linguistic disciplines indicates that CDA shares some common features with these approaches which, in turn, affects the interpretative process of discourse within its framework.

Tracing the theoretical framework of CDA, one can find that some CD analysts have already come to terms with the linguistic methodology that is used under the umbrella of this discipline. Other CDA practitioners, however, are still engaged in finding inconsistencies within the framework of CDA. They still feel the gap between theory and practice, and fail to assimilate the contextual atmosphere of texts with the analytical and interpretative framework of CDA. This shows that much of the discrepancy among $\mathrm{CD}$ analysts regarding its theoretical framework owes to CDA's interpretative nature. The DRA which this paper proposes therefore seeks to be a theoretical defence for CDA's multiplicity of interpretation. It allows more participation in the interpretation process of discourse on the part of readers. Under the theoretical umbrella of DRA, ordinary readers can easily attach their world knowledge to any piece of discourse because it offers much freedom for readers and $\mathrm{CD}$ analysts to find a theoretical base to their different interpretations.

\subsection{CDA and Poststructuralist Theories (Deconstruction and Reception Theories)}

The idea of deconstructing texts in order to discover the hidden meanings is a shared feature of both CDA and the deconstruction theory. Guerin, Labour, Morgan, Reesman, \& Willingham (1999) see that the term deconstruction comes to mean that texts do not have determinate meanings, but they are deconstructed to produce new ones. Meyer (1983) argues that deconstructionists insist that a text cannot be claimed to convey only one meaning because the diversity of meanings is the ultimate product of the deconstruction theory. Deconstructionists believe that language has the ability to convey more meanings than those expressed by and grasped from the mere linguistic features of texts. They also emphasize that language has the authority to stimulate the readers' interpretative potentialities to attach more than one meaning to the same text. Accordingly, any text, which is said to be grasped independently, is supposed to be deconstructed in order to divulge its connections to other conflicting and incompatible meanings.

Foucault (1980) leads the poststructuralist view that sees discourse as a mirror which reflects the social world of its users. He believes that meaning of discourse cannot be attained only by a mere analysis of linguistic tools, but rather through the conventional connection between different practices of discourse and its orders in society. Angermuller, Maingueneau, \& Wodak (2014, p. 361), for instance, emphasize the theoretical relationship between discourse and poststructuralism by arguing that the fundamental concern of all CDA's approaches is "to reveal how complex social problems are linguistically represented and to suggest ways of challenging them, deconstructing them, understanding them and opening up possibilities of overcoming them." A deconstructive analysis of discourse, thus, proves its inclination to different readings which eventually lead to different interpretations.

According to Allan (2000), there is no independent meaning of discourse. The contextual atmosphere in which discourse is produced and consumed has the power to reshape its meaning. He points out that the social, cultural and historical dimensions work effectively to formulate meanings of discourse. Thus, there are certain elements that have great influence on the process of interpreting a text. These elements are integrated with each other in order to create conformity between the historical and contextual environment of discourse and its meaning. Gadavanij (2002) sees this harmonious relationship between different factors within a text as an advantage which protects it from literal interpretation. Since CDA is "heavily reception/reading oriented, with no strongly explicit account of production, or of producers" (Kress, 1996, p. 16), it allows the reader to reinterpret and deconstruct texts to discover new meanings.

Reception theory or reader-response movement, according to Norris (1982), emerged in 1960s in reaction to the formalism of the new criticism movement that dominated and shaped the literary atmosphere during the 1930s, 1940s and 1950s. This theory highlights the process of reading as essential in understanding the meaning of texts. Reception theory, according to Jauss (in Newton, 1997), tries to incorporate the interests of readers with the embodied experiences of texts. It advocates the renewal readership process because it always brings new experiences and different meanings 
to texts. Fish (1976) emphasizes that the past experiences of the readers are of great importance in the interpretation of texts. He states that such experiences should be described and studied if one wants to reach an appropriate meaning for any text. Since reception theory defends the role of readers, texts are not supposed to have one definite meaning. Iser (1997) also argues that reading is the driving force which adds significance to texts. A text, therefore, becomes a newborn entity in the hands of its readers. Given that the reader dominates the greatest part in the process of producing different meanings of a text, and given the fact that CDA is also a reception/reading oriented approach, one can claim that there is also a close relationship between reception theory and CDA. Both approaches give priority for the reader to be the source from which texts come to life and new meanings arise.

\section{Literature Review}

The diversity of methods which CDA adopts is clearly shown in the writings of many researchers, such as Fairclough (1992; 2009; 2010; 2013), Fairclough et al. (2011), Van Dijk (1993; 1996; 2001; 2014), and Wodak and Meyer (2009). In spite of this methodological diversity, it leads to much criticism against CDA. Emphasizing the miscellaneous models and approaches CDA absorbs within its theoretical agenda, Fairclough et al. (2011) argues that CDA is an interdisciplinary movement which includes different approaches, and each abounds in various theoretical models. Among the approaches which address CDA's theoretical framework are Fairclough's (2010), Van Dijk's (1993; 2009; 2014), Wodak's (1995), Van Leeuwen's (2009), Jäger and Maier (2009), and Pennycook's (2001) approaches. The paper gives a glimpse to these approaches in this section, and then suggests a possible extension of these approaches by introducing a deconstructive, reader-oriented approach to critical discourse analysis.

Fairclough (2010, p. 4) describes his approach to CDA as "dialectical-relational." He maintains that CDA does not solely attempt to analyze discourse "in itself", but rather it discusses "the dialectical relations between discourse and other objects, elements or moments, as well as analysis of the internal relations of discourse." Fairclough's approach authorizes CD analysts to investigate the different argumentative relations between discourse and the other elements that affect their interpretations; be they social, economic, or political. In his Language and Power, Fairclough (1989; 2013) presents a framework for the analysis of discourse with three dimensions. The first dimension focuses on the linguistic features of text from lexical, grammatical, and pragmatic perspectives. The second dimension conceives discourse as an interactional act which is produced and consumed in society. The third dimension regards the social practices in discourse in which notions of power, dominance, and hegemony are produced, reproduced and practiced. Fairclough's model, therefore, deals with the processes of both production and reception in discourse, the thing which correlates with his perspective of discourse that it should pass through three stages: description, interpretation and explanation (Fairclough, 1992).

Van Dijk's socio-cognitive model to discourse offers "a multidisciplinary approach which chooses and elaborates theories, methods and empirical work as a function of their relevance for the realization of socio-political goals." (Van Dijk, 1993, p. 252) This approach tries to reveal the linguistic devices in written and spoken discourse which are used to exercise power. To Van Dijk (2009), the socio-cognitive approach is based on the idea that the study of cognition is significant in the study of discourse, communication and interaction as well as the mental, discursive, and societal relationship. Van Dijk (2014, p. 12) sees discourse to be "a form of social interaction in society." He also emphasizes the triangular reciprocal relationship between discourse, cognition and society in order to create proximity between micro and macro structures in social sciences. This idea is also highlighted by Waugh, Catalano, Al Masaeed, Do, \& Renigar (2015) when they emphasize the significance of the socio-cognitive approach in fulfilling the gap between the linguistic and non-linguistic levels of analysis.

Depending on the ideas of Habermas, Ruth Wodak (1995) presents her approach to discourse and discusses the strategies that influence the existence of discourse disorders represented in a specific context. Wodak developed what is called the discourse historical approach giving valuable contribution to discourse studies. This approach blends together the background information of readers and the linguistic features of texts in the analysis and interpretation of written and/or spoken texts. According to Wodak and Ludwig (1999), the interpretation of any text differs from one reader to another depending on his/her world knowledge. They maintain that the notion of final interpretation is found missing in CDA. Wodak (2009) emphasizes two important elements in her approach: investigating the strategies used for positive self- presentation and negative other- presentation; and deconstructing the linguistic means and linguistic realization of the discursive practices.

Van Leeuwen's social actors approach is based on the idea that "discourses are recontextualizations of social practices." (Van Leeuwen, 2009, p. 144) Van Leeuwen pays great attention to social practices which for him are important elements in interpreting discourse. These social practices have a connection with the cognitive background of the readers who indubitably affect the representations of such social practices. According to Waugh et al. (2015), Van Leeuwen's approach makes a connection between the reproduction of social structures by discourse participants and the Foucauldian notion which considers the different types of discourse to be constructions of society that reflect the various facets of real life. This approach then emphasizes the role of social practices which is influenced by the readers' responsiveness to the discursive act. Here, the sociological dimension is more important than the linguistic one in the interpretation of texts.

Jäger and Maier (2009) develop their dispositive approach which is mainly based on Michel Foucault's discourse theory. Dispositive analysis "aims to identify the knowledges contained in discourses and dispositives, and how these knowledges are firmly connected to power relations in power/knowledge complexes" (Jäger and Maier, 2009, pp. 3435). Waugh et al. (2015) speak about the analytical nature of the dispositive approach saying that it is mainly concerned 
with the macro structures of texts rather than the micro features because it focuses on the "non-linguistic elements" (p. 86) rather than the linguistic. The main objective of this approach, according to Waugh et al. (2015), is to make a connection between discursive practices, non-discursive practices, and materialization (objects produced by human action). These elements are based on "knowledge that is transmitted through discourse" (p. 87). The focus on the nonlinguistic elements in Jäger and Maier's model paves the way for more freedom in the interpretation of discourse and encourages the ordinary reader to have his own word which is formed via a deconstructive reading of texts.

The critical applied linguistics approach of Pennycook (2001) is based on the idea of remaking the connections between discourse, language learning, language use, and the social and political contexts in which these occur. To Waugh et al. (2015), critical applied linguistics approach critically analyzes sites of inequality which people face due to social, cultural, economic, and political conditions. The main concern of this approach is to fulfil the gap between theory and practice which is mainly focused on as one of the critiques launched against CDA. In his preface to his book Critical Applied Linguistics: a critical introduction (2001), Pennycook prefers the term 'critical applied linguistics' as a description of his work. He differentiates between CDA and critical applied linguistics when he classifies the former to be one of the modernist approaches of language analysis, and describes the latter as being a postmodernist critique.

\section{Methodology}

During the course of this study, a general assessment was made of the theoretical approaches of CDA, by showing the core concerns which these approaches adopt for various interpretations in order to find out missing gaps in the process of interpretation that can be fulfilled by the new perspectives of the DRA explored in this paper.

\subsection{General Assessment to CDA's Approaches}

The CDA approaches so far seem inclined to fulfil the gap between theory and practice by emphasizing the sociological dimension in the interpretation of discourse. They highlight the importance of the non-linguistic over the linguistic by stating that (i) the relationship between discourse and society is dialectical (Fairclough), (ii) the mental, discursive, and societal relationship should be highlighted (Van Dijk), (iii) there is no final interpretation for texts; and linguistic features of texts should be deconstructed (Wodak), (iv) social practices are important elements in the interpretation of discourse (Van Leeuwen), (v) the non-linguistic (macro structures) is more important that the linguistic (micro structures) (Jäger and Maier), and (vi) the relationship between discourse and social practices should be reconsidered (Pennycook).

A close assessment of these approaches during the course of this research has shown that these approaches sometimes contradict what already exists in reality. They do address CDA for its thematic and theoretical agenda but leave the door open for much criticism, specifically with regard to its interpretative nature. Interpretation in CDA is influenced by the different readings of different readers who interpret texts according to their world knowledge, which ultimately shapes and reshapes their interpretative atmosphere. Since readers are supposed to have different ideologies which formulate their cognitive world, their interpretations are not expected to be the same.

There are always new interpretations in CDA; hence it needs a theoretical shield to advocate its critiques concerning multiplicity of interpretation. A theoretical extension is required, not to completely answer these shortcomings, but to lessen the amount of criticism launched against CDA. This study has emphatically suggested introducing a deconstructive, reader-oriented approach to CDA in order to provide a new theoretical base to the paradigm which in turn can function to diminish some of the critiques levelled against its interpretative nature.

\section{Discussion and Findings}

\subsection{A Deconstructive, Reader-oriented Approach to CDA}

The deconstructive, reader-oriented approach (DRA) depends on the notion that texts/discourses are ready to be deconstructed and decontextualized in order to discover new meanings. It is derived from the deconstruction theory with all its principles and roots which are presented by Derrida in his on Grammatology. Both deconstruction theory and CDA are closely related to each other in the sense that both movements are said to be reception-oriented. Deconstructionists, on one hand, always call for dismantling texts from its meanings and introducing new ones according to the process of reception; while on the other hand, critical discourse analysts argue for the indeterminacy of meaning in CDA. Consequently, one can say that both movements are considered to be sites for meanings struggles.

$\mathrm{CD}$ analysts offer a diversity of approaches and models in the interpretation of discourse; allowing the interweaving of different linguistic levels in the process of producing new meanings. Deconstructionists' main concern is also to end the notion of independent meaning of texts. Both of them tend to end the sanctity of discourses/texts. The reception theory scholars also come to terms with their main principle of dealing with discourse which advocates terminating the dominance of authors completely over their texts. Texts/discourses are open to different processes of reading which ultimately result in different interpretations that may be completely different from the real meaning intended by the author. Now, we can identify the triadic relationship between CDA, the deconstruction theory, and the reception theory. The three approaches open the door for the possibility of familiarizing new interpretations for discourse.

It is important to mention here that the idea of taking a poststructuralist approach to CDA was firstly introduced and discussed by Fairclough and Chouliaraki (1999). This appeared in their book entitled Discourse in Late Modernity which crowned Fairclough's efforts, particularly, in expanding the theoretical framework he was working with for CDA. Discourse in Late Modernity sheds lights on Fairclough and Chouliaraki's approach which might be described as an uneasy mix of post-Marxism, critical realism, and poststructuralism. Actually, they go so far as to declare in this book 
that they are, "working within a poststructuralist perspective" (p. 32). Nevertheless, worthy to mention, Fairclough himself came to the view that there was too much incommensurability in his thinking regarding his poststructuralist view. A clear evidence for Fairclough's conversion is his thinking after the publication of Discourse in Late Modernity in 1999 as he moved much more decidedly into critical realism and away from poststructuralism. Fairclough's new approach was firstly proclaimed in a conference paper entitled 'Realism Discourse and Deconstruction' (2001), and effectively clarified in his Critical Realism and Semiosis (2004). However, the introduction of the term Deconstruction in Fairclough's above works does not mean that introducing a deconstructive, reader-oriented approach to CDA is not a novel idea. Conversely, introducing such a deconstructive, reader-oriented approach to CDA emphasizes Fairclough's and Chouliaraki's thinking, and ends the suspicion of the former concerning the connection between CDA and deconstruction theory.

\subsection{DRA: A New Paradigm of Interpretation}

The theoretical flexibility of CDA to offer multiple meanings and challenged readings of discourse has been encountered with some sort of criticism. It paves the way for more ideologically-laden interpretations as well as for what Blommaert (2005b, p. 32) puts it "predominance of biased interpretations," which sometimes violates the meaning the linguistic features of texts carry. This view is supported by Billig (2008) when he stated CDA's failure to be objective in a way which assures that the language of CD analysts will never be influenced by the ideological features which they try to find in the language of others.

Similarly, the latitude of meaning within the interpretative framework of CDA allows the domination of the macro/ non-linguistic structures over the micro/ linguistic ones. The ascendancy of the non-linguistic over the linguistic can be easily touched from the aforementioned theoretical approaches to CDA. However, it is also observed that some critical discourse analysts try to use the interpretative merits of CDA and offer to find justifications for their different interpretations of the same discourse. They subjugate the linguistic to the non-linguistic and actually defend the inappropriate at the expense of the appropriate which has challenged the linguistic sovereignty of discourse.

This gives strength to the contention of this research that an introduction of a deconstructive, reader-oriented approach to CDA in the process of searching for the meaning source of discourse can help critical discourse analysts to find out the hidden ideologies of such discourses. The DRA facilitates the task of CD analysts to prove the linguistic relativity of both the micro and the macro-structures of discourse. This linguistic relativity is used to make a connection and to establish a logical relationship between the discursive strategies manipulated in discourses and reality. Having agreed that readers are completely different in their ideologies, it follows then that their ideological diversity ultimately leads to the production of various meanings. The reader's motivation to uncover the hidden ideologies in discourse and his inclination to use and/or impose his own ideology, either intentionally or unintentionally, will definitely direct him to deconstruct discourse in order to discover new meanings which certainly cope with his world knowledge and cognitive background.

This process of deconstructing discourse to produce new meanings, which depends on the notion of readership and responsiveness, is the ultimate goal DRA seeks to achieve. Here, DRA can fulfil in part the gap between theory and practice by offering critical discourse analysts the freedom to incorporate the contextual environment of discourse with the interpretative framework of a new paradigm. It also lays down a theoretical extension that allows different readings of different readers to shape and reshape the final interpretation of discourse without being blamed for subjugating the linguistic to the non-linguistic.

\subsection{DRA and its Contributions}

The question now is, why do we need to introduce such a deconstructive, reader-oriented approach to CDA? The answer lies in the fact that the interpretative nature of CDA as well as its flexibility in absorbing different meanings for the same discourse encourages us to proclaim its deconstructive and reader-oriented nature. This indicates the relevance of DRA to the interpretative framework of CDA for some reasons. This study has collected evidence that could be potential contributions of adopting the DRA approach.

First, investigating the work of all critical analysts shows that in their attempt to expose hidden ideologies and discursive irrationalities in discourse, they try to divide any discursive act into its smaller parts and seek "to understand and explain the dialectical relationships between meaning and other elements of social practices" (Hughes\& Sharrock, 2007, p. 337) in order to discover more meanings for the same piece of discourse. Bloor and Bloor (2013) clarify that the process of investigating meaning by breaking it down into its components is known as deconstruction. Consequently, the work of critical discourse analysts of looking out for hidden ideological positions in discourse is a deeply-rooted principle of the deconstruction theory. This process of discovering more meanings emphasizes the indeterminacy of CDA, a characteristic for which CDA is criticized. The DRA attempts to end such blame by introducing new theoretical deconstructive features to CDA and offering the language users the freedom to discover the hidden ideologies in discourse, which is considered to be one of the main goals of CDA. Since discourse depends upon a number of words and structures which are linguistically interwoven to carry ideological significance, the deconstruction of these discourses will provide a theoretical basis upon which the language users can attach their new ideologies to the words and structures of these discourses. This will ultimately lead to the production of more meanings for the same discourse.

Second, introducing DRA to CDA fulfils in part the gap between analysis and interpretation. This is also discussed by Widdowson (2012) who differentiates between analysis and interpretation proposing that in the process of 
interpretation, the contextual and pretextual circumstances of texts should be involved, whereas analysis is only confined to mere linguistic features of texts. He maintains that during the process of reading, "we focus selectively on some features and disregard others, regulating our attention according to what our own pretextual purpose is in reading the text in the first place-what we are reading for." (Widdowson, 2012, p. 9) According to Widdowson (2012), the argumentation concerning the difference between analysis and interpretation stems from the disparity between the ways in which meanings are encoded in linguistic forms and the ways through which these linguistic forms are conceived and interpreted by the language users. For him "interpretation is subject to contextual and pretextual conditions and analysis is not" (p. 11). He maintains that meanings "are not discovered in texts but derived from them and are therefore always conditional and indeterminate, with pretext the key regulating factor" (Widdowson, 2012, p. 3).

The complete dependence on pretextual conditions of texts in Widdowson's view makes him claims that there is no authoritative interpretation for texts. The meaning of texts is never discovered but invented. This element of inventing new meanings of texts comes not as a result of textual analysis, but due to contextual and pretextual circumstances. Texts, for Widdowson (2012), remain texts without change despite the passage of time and the changes that may take place in the world; however, meanings are constantly changed from time to time according to their new contexts and pretexts. Texts, he further argues, have "fixed and determinate linguistic object, but they give rise to variable discourses" (p. 7). These discourses, or interpretations, are formed and reshaped according to the time when they are produced, the persons who produce and perceive them and the purpose of their production. He has thus argued that we should "trust the text" if we are concerned only with textual analysis (depending on the mere linguistic features of texts), and we should "distrust the text" in case of being concerned with discourse interpretation (depending on contextual and pretextual conditions of texts). Here he therefore differentiates between critical discourse analysis and critical discourse interpretation. (Widdowson, 2012, pp. 13-14) DRA aims to set a compromise between Widdowson's analysis and interpretation in the sense that it offers a theoretical basis for the analysis of discourse in connection with employing the contextual features of texts during the process of deconstructing them. Within DRA, we do not need to trust texts, distrust them or distrust their analysts; rather, we only need to deconstruct them.

Third, this study has found that proposing DRA to CDA will diminish the amount of criticism which is levelled against its interpretative framework concerning plurality of meaning. It will also establish some sort of exoneration for its theoretical shortcomings in this point. This does not mean that DRA opens the door for disregarding the textual features of texts, or calls for the domination of the non-linguistic over the linguistic. However, this new approach, like other CDA's approaches, seeks to emphasize the integration of both the micro and the macro structures in the interpretation of discourse by offering much interpretative freedom for the ordinary reader to bring his own meaning. Such interpretative freedom, according to Flowerdew (2013, p. 189), is sought because "the interpretation of the lay reader is ignored" in CDA. Ordinary readers are not like those specialized CD analysts in processing and understanding information of discourse. They do not have the adequate previous knowledge or the linguistic discursive competency which enable them to observe and discover the hidden ideologies in discourse. DRA allows readers to deconstruct texts depending on their ordinary knowledge and experience. It also provides them with a theoretical shield to defend their interpretations if they partially run counter to the linguistic features of texts or differ from the interpretations of CD analysts.

Fourth, based on Widdowson's argumentation, this research has thus concluded that the term 'analysis' is attributed to critical discourse by analysts who depend only on the linguistic features of texts. In this case, according to Widdowson (2012), meaning is described to be deterministic or final. The word 'interpretation', on the other hand, is attached to critical discourse when interpreters tend to focus on the contextual and pretextual conditions of texts. Discourse in this case cannot be claimed to have only one or final meaning, yet it is open to a variety of indeterminate interpretations. This research has also encountered other classifications for CDA that are derived from its deconstructive nature and therefore infers that in interpretation, there is no need for the word 'critical'; rather 'deconstructive' is a more preferred term. This research strongly recommends the term 'deconstructive discourse interpretation'. substituting the word 'critical' with 'deconstructive' and 'analysis' with 'interpretation' reduces the criticism that is related to the word 'critical' (Billig, 2002; Wodak \& Meyer, 2009) since the word 'critical' means 'positive', according to these scholars, while 'noncritical' is supposed to be the opposite. Furthermore, the word 'interpretation' reduces the critique against CDA's theoretical inability to take context into account and its reliance on the analyst's views of texts' meaning (Breeze, 2011).

Fifth, it is evident among all critical discourse analysts that ideology is one cornerstone of discourse interpretation. This is also emphasized by Bloor and Bloor (2013, p. 10) when they clarify that CD analysts should be completely aware of the fact that any critical discourse analysis of texts is "ideologically based." It is also clear that ideology is not genetically acquired but it is socially and culturally conditioned. It is learned from the interaction with others; be they the family, the school, or any source where individuals interact and communicate with each other. The fact that ideological backgrounds of individuals are socially acquired leads to the assumption that they are supposed to have different ideological backgrounds. These backgrounds are the driving force in the process of discourse interpretation. The ideological discrepancy among individuals functions to produce different interpretations for the same text. This interpretative freedom is one of the points CDA is blamed for. This research study has therefore believed in this premise that introducing a deconstructive approach to CDA will help to undermine the criticism against CDA concerning the latitude of interpretation.

Sixth, accommodating DRA to be a theoretical extension of CDA's interpretative framework ends the argument that interpretation in CDA is based on preconceived ideas rather than objective analysis (Tyrwhitt-Drake, 1999). TyrwhittDrake (1999) argues that critical discourse analysis depends to a large extent on opinions and values of analysts rather 
than on facts. He believes that interpretation in critical discourse analysis is predetermined, and that any act of textual analysis supports and reinforces such preconceived interpretations. The deconstructive, reader-oriented approach to CDA also supports Flowerdew's (1999) idea that CDA is reflexive and that the nature of interpretation within its framework is a product of the dialectical relation between discourse and context. DRA reinforces such a dialectical relation between discourse and context by creating some sort of reciprocity between texts and readers that allows the latter to deconstruct the former in order to produce new meanings. This research study was therefore in consistent with this ideology.

Finally, despite the fact that DRA authorizes readers to produce different interpretations for the same text, the diversity of reading does not undermine the idea that any act of reading involves a combination of the textual properties of texts and the interpretative practices and ideologies which are brought and injected on them. The range of potential interpretations then will be confined not only to the textual features of the text but also the responsive deconstructive reading of its readers which is shaped by their cognitive background, the aspects of their world knowledge, and the interaction they create with texts. This study has emphasized the absence of the final interpretation in CDA that might confirm its deconstructive nature and open the door for DRA to take its position among CDA's theoretical approaches.

\section{Conclusion}

This paper originated from a diversity of paradigms in CDA concerning its interpretative task, which had a wide range of linguistic analyses to emphasize the interrelations of the discursive practices in a society. This diversity had also surrounded CDA's theoretical agenda with some doubts regarding the nature of its interpretative framework. This had led some linguists to accuse CDA as being a personally-based discipline rather than a well-theorized paradigm. Moreover, the open nature of interpretation in CDA had subjected to more opposition, more differences, and more meanings, which in turn makes readers suspect the interpretative nature of this model and felt the need of an alternative approach.

This paper has attempted to offer this alternative by introducing a deconstructive, reader-oriented approach (DRA) to critical discourse analysis as a contribution to its theoretical framework. The paper has emphasized the reciprocal relationship between $\mathrm{CDA}$ and both the deconstruction and the reception theories. It also shows that introducing a deconstructive, reader-oriented approach to CDA is relevant to its interpretative nature enough to circumvent and lessen a part of the criticism levelled against its interpretative framework concerning plurality of meaning; and to establish some sort of exoneration for its theoretical shortcomings. This paper clarifies that discourse interpretation is an argumentative issue. The latitude of interpretation under the guise of CDA varies according to not only the type of text but also the responsive deconstructive reading of its readers. This paper also demonstrates that CDA does not only analyze texts, but also deconstructs them. This makes CDA's theoretical framework ready to accept DRA since it can theoretically advocate the idea that there are always new interpretations in discourse.

\section{References}

Allan, G. (2000). Intertextuality: The new critical idiom. London: Routledge.

Angermuller, J., Maingueneau, D., \& Wodak, R. (Eds.) (2014). The discourse studies reader: Main currents in theory and analysis. John Benjamin Publishing Company.

Billig, M. (2002). Critical discourse analysis and the rhetoric of critique. In G. Weiss and R. Wodak (Eds.), Critical discourse analysis: Theory and interdisciplinarity. London: Palgrave Macmillan, (pp. 35-46).

Billig, M. (2008). The language of critical discourse analysis. The case of nominalization. Discourse\& Society, 19 (6): 783-800.

Blommaert. J. (2005a). Discourse: An introduction. Oxford; Oxford University Press.

Blommaert, J. (2005b). Discourse: Key topics in sociolinguistics. Cambridge University press.

Bloor, M. \& Bloor, T. (2013). The practice of critical discourse analysis: An introduction. London and New York: Routledge.

Breeze, R. (2011). Critical discourse analysis and its critics. In Pragmatics, 21:4. 493-525.

Chouliaraki, L. \& Fairclough, N. (1999). Discourse in late modernity: Rethinking critical discourse analysis. Edinburgh: Edinburgh University Press.

Fairclough, N. (1989). Language and power. London \& New York: Longman

Fairclough N. (1992). Discourse and social change. Cambridge, UK: Polity.

Fairclough, N. (1995a). Critical discourse analysis: The critical study of language. London \& New York: Longman.

Fairclough, N. (1995b). Media discourse. London: Edward Arnold.

Fairclough, N. (2009). A dialectical-relational approach. In R. Wodak \& M. Meyer (Eds.), Methods of critical discourse analysis (162-186). Thousand Oaks: Sage.

Fairclough, N. (2010). Critical discourse analysis: The critical study of language. (2 ${ }^{\text {nd }}$ ed.). Routledge.

Fairclough, N. (2013). Language and power. (2 ${ }^{\text {nd }}$ ed.). Routledge. 
Fairclough, N., Jessop, B., \& Andrew S. (2004). Critical realism and semiosis. In Joseph, Jonathan \& John, M. Roberts (Eds.). Realism discourse and deconstruction. London \& New York. Routledge. (pp 23-42).

Fairclough, N., Muldering, J., \& and Ruth W. (2011). Critical discourse analysis. In T. A. Van Dijk (Ed.), Discourse studies, 357-378. Thousand Oaks: Sage.

Fairclough, N., Pardo, S. \& Szerszynski, B. (2003).Critical discourse analysis and citizenship. In Bora, A. \& Hausendorf, H. (Eds.), Constructing citizenship (pp. 1-17). John Benjamins Publishing Company.

Fish, S. (1976). Interpreting the variorum. In Lodge, D. (Ed.), Modern criticism and theory: A reader (pp. 310-329). London \& New York: Longman.

Foucault, M. (1980). Power/knowledge: Selected interviews and other writings, edited by C. Gordon, translated by Gordon et al. New York: Panthean Books.

Flowerdew, J. (1999). Description and interpretation in critical discourse analysis. Journal of Pragmatics, 31, 10891099, Elsevier.

Flowerdew, J. (2013). Discourse in English language education. Routledge.

Fowler, R. (1986). Linguistic criticism. Oxford \& New York: Oxford University Press.

Fowler, R. (1996). On critical linguistics. In Carmen Rosa Caldas- Coulthard \& Malcolm Coulthard (Eds.), Texts and practices: Readings in critical discourse analysis (pp. 15-31). London \& New York: Routledge.

Fowler, R. \& Kress, G. (1979). Critical linguistics. In R. Fowler, R. Hodge, G. Kress \& T. Trew (Eds.), Language and control ( pp. 185-213). London: Routledge \& Kegan Paul.

Gadavanij, S. (2002). Intertextuality as discourse strategy: The case of no-confidence debates in Thailand. In Nelson, D. (Ed.), Leeds working papers in linguistics and phonetics, 9, 35-55.

Guerin, W., Labour, E., Morgan, L., Reesman, J., \& Willingham, J. (1999). A handbook of critical approaches to literature. New York \& Oxford. Oxford University Press.

Hughes, J. \& Sharrock, W. (2007). Theory and methods in sociology: An introduction to sociological thinking and practice. Palgrave: Macmillan.

Iser, W. (1997). Indeterminacy and the reader's response. In Newton, K. M. (Ed.), Twentieth-century literary theory (2 ${ }^{\text {nd }}$ ed.) (pp.195- 199). London: Macmillan Press Ltd.

Jäger, S. \& Maier, F. (2009). Theoretical and methodological aspects of Foucauldian critical discourse analysis and dispositive analysis. In R. Wodak \& M. Meyer (Eds.), Methods of critical discourse analysis, (pp.34- 61). Thousand Oaks: Sage.

Kress, G. (1996). Representational resources and the production of subjectivity: Questions for the theoretical development of critical discourse analysis in a multicultural society. In Coulthard, C. \& Coulthard, M. (Eds.), Texts and practices: Readings in critical discourse analysis (pp. 15-31). London and New York: Routledge.

Meyer, M. (1983). Thinking and writing about literature. Boston: Bedford books of ST. Martin's Press.

Newton, K. M. (Ed.) (1997) Twentieth-century literary theory. London: Macmillan Press Ltd.

Norris, C. (1982). Deconstruction: Theory and practice. (Revised ed.). London: Routledge.

Pennycook, A. (2001). Critical applied linguistics: A critical introduction. Lawrence Erlbaun Associates, Publishers, Mahwah, New Jersy: London.

Teo, P. (2000). Racism in the news: A critical discourse analysis of news reporting in two Australian newspapers. Discourse \& Society, 11, 7-49. London: Sage Publications.

Tyrwhitt-Drake, H. (1999). Resisting the discourse of critical discourse analysis: Reopening a Hong Kong case study. Journal of Pragmatics 31, 1081-1088. Elsevier.

Van Dijk, T. A. (1989). Structures of discourse and structures of power. In J. A. Anderson (Ed.), Communication yearbook (pp. 18-59). Vol. 12. Newbury Park, C A: Sage.

Van Dijk, T. A. (1993). Principles of critical discourse analysis. Discourse \& Society, 4 (2), 249-283. London: Sage.

Van Dijk, T. A. (1996). Discourse, power and access. In Coulthard, C. \& Coulthard, M. (Eds.), Texts and practices: Readings in critical discourse analysis (pp. 84-104). London \& New York.

Van Dijk, T. A. .(2001) Critical discourse analysis. In Deborah Schiffrin, Deborah Tannan \& Heidi E. Hamilton (Eds.), The handbook of discourse analysis (pp. 352-392). Blackwell.

Van Dijk, T. A. (2009). Critical discourse studies: A socio-cognitive approach. In R. Wodak \& M. Meyer (Eds.), Methods of critical discourse analysis (pp. 62- 86). Thousand Oaks: Sage.

Van Dijk, T. A. (2014). Discourse and knowledge: A sociocognitive approach. Cambridge University Press.

Van Leeuwen, T. (2009). Discourse as the recontextualization of social practice: A guide. In R. Wodak \& M. Meyer (Eds.), Methods of critical discourse analysis. Thousand Oaks:Sage. (pp. 144-161) 
Waugh, R. L., Catalano, T., Al Masaeed, K., Do, T. H., \& Renigar, P. G. (2015). Critical discourse analysis: Definition, approaches, relation to pragmatics, critique, and trends. In Capon, A. \& Mey, L. Jacob (Eds.), Interdisciplinary studies in pragmatics, culture and society (pp. 71-135). Springer.

Weiss, G. \& Wodak, R. (Eds.) (2003) Critical discourse analysis: Theory and interdisciplinarity. Palgrave Macmillan Ltd.

Widdowson, H. (2012). The pretext of interpretation. In Navratilova, O. \& Povolna, R. (Eds.), Discourse interpretation: Approaches and applications (pp. 3-18). Cambridge Scholars Publishing.

Wodak, R. (1995). Critical linguistics and critical discourse analysis. In Verschueren et al. (Eds.), Handbook of pragmatics. (pp. 204- 210). Amsterdam: Benjamins.

Wodak, R. \& Ludwig, C. (1999). Challenges in a changing world: Issues in critical discourse analysis. Passagen Verlag.

Wodak, R. \& Meyer, M. (Eds.) (2009). Methods of critical discourse analysis. London: Thousand Oaks: Sage. 